\title{
Effect of Sympathetic Nerve Stimulation on Cerebral Blood Flow in Newborn Piglets
}

\author{
L. CRAIG WAGERLE, SAVITRI P. KUMAR, AND MARIA DELIVORIA-PAPADOPOULOS \\ Department of Physiologl: University of Pennsylvania School of Medicine. Philadelphia. Pennsy.trania 19104
}

\begin{abstract}
The purpose of this study was to determine the effect of sympathetic nerve stimulation on regional cerebral blood flow during the first 3 wk of postnatal development in piglets. Forty-one piglets ranging in age from 2 to 24 days were studied while anesthetized with $30 \% \mathrm{~N}_{2} \mathrm{O}$, paralyzed and mechanically ventilated $\left(\mathrm{PaCO}_{2}\right.$ $=35-40 \mathrm{~mm} \mathrm{Hg}$ ). Regional cerebral blood flow was measured with tracer microspheres $(15 \pm 1 \mu \mathrm{m})$ during electrical stimulation $(15 \mathrm{~Hz}, 15 \mathrm{~V}, 3 \mathrm{~ms})$ of the right cervical sympathetic trunk. Sympathetic stimulation decreased blood flow to the ipsilateral cerebrum (gray and white matter) $(-15 \pm 2 \%)$, hippocampus $(-9 \pm 2 \%)$, choroid plexus $(-50 \pm 5 \%)$, and masseter muscle $(-93 \pm 2 \%)$ compared to the contralateral side where blood flow to these regions was $74 \pm 4,45 \pm 2,258 \pm 26$, and $24 \pm 4$ $\mathrm{ml} / \mathrm{min} / 100 \mathrm{~g}$, respectively (mean $\pm \mathrm{SEM} ; p \leq 0.05$ ). The magnitude of the reduction in cerebral blood flow was not dependent on postnatal age as no significant differences were noted when the piglets were grouped according to age. Hypercapnia $\left(\mathrm{PaCO}_{2}=64 \pm 5 \mathrm{~mm} \mathrm{Hg}\right)$ increased blood flow 2- to 4 -fold above control in all brain regions except the choroid plexus. The effect of sympathetic nerve stimulation was augmented during hypercapnia where blood flow to the ipsilateral cerebrum, hippocampus, and caudate nucleus was decreased by $-34 \pm 4,-23 \pm 5$, and $-16 \pm 3 \%$, respectively. Activation of sympathetic nerves can reduce blood flow to specific brain regions during control conditions and these effects are larger in hyperemic conditions such as hypercapnia. These data demonstrate that sympathetic nerves are present and completely developed at birth and, when sufficiently activated, capable of influencing regional cerebrovascular resistance in the newborn piglet. (Pediatr Res 20: 131-135, 1986)
\end{abstract}

\section{Abbreviation}

CBF, cerebral blood flow

Studies in noncerebral vascular beds have shown that the sympathetic nervous system is immature at birth in most species and considerable postnatal development occurs with regard to the force of smooth muscle contraction, vascular innervation and function, and adrenoceptor concentration and function (1). Histochemical and pharmacological studies have indicated that adrenergic mechanisms in cerebral vessels of mice and rats exhibit considerable postnatal development as well $(2,3)$.

Despite the apparent immaturity of the sympathetic nervous

Received May 29. 1985: accepted September 18. 1985.

Correspondence I. Craig Wagerle, Ph.D.. Department of Physiology, University of Pennsylvania School of Medicine. Philadelphia, PA 19104.

Supported by National Institute of Health Grants T35-HD-07217-10 and R01HD-15973. system at birth, studies of the newborn cerebral circulation in vivo suggest a potent sympathetic constrictor effect in the asphyxiated newborn dog (4) and hypoxic lamb (5). The effect of sympathetic nerves on $\mathrm{CBF}$ in the nonhypoxic, eucapnic newborn animal, however, have not been examined. Additionally, sympathetic effects on CBF may change substantially over the first days of postnatal development. The present experiments were designed to characterize the effect of sympathetic nerve stimulation on CBF over the first $3 \mathrm{wk}$ postnatally.

In adult animals the effect of sympathetic nerves on CBF are thought to be minimized by compensatory vasodilation of intraparenchymal arterioles (6). Since the cerebral circulation in newborn animals appears to be less responsive to various vasoactive stimuli (7-9), we postulated that in the newborn, intraparenchymal arterioles may not dilate sufficiently to offset sympathetic vasoconstriction. To examine this possibility, additional experiments were performed to study the effects of sympathetic nerve stimulation during hypercapnic hyperemia.

\section{METHODS}

Animal preparation. Studies were performed on 41 newborn Yorkshire piglets ranging in age from 2 to 23 days (mean age $=$ $7.6+0.7$ days). Piglets were anesthetized with $3-4 \%$ halothane. Core body temperature was monitored and maintained at $39^{\circ} \mathrm{C}$ with a warming blanket. Following local anesthesia (2\% lidocaine) a tracheostomy was performed and catheters were placed into a femoral artery and vein, a brachial artery, and into the left atrium via a left thoracotomy. Animals were paralyzed $(0.5 \mathrm{mg}$ pancuronium bromide) and mechanically ventilated. Both left and right cervical sympathetic trunks were isolated and bipolar electrodes placed around each nerve immediately caudal to the superior cervical sympathetic ganglion and the nerve was crushed proximal to the electrodes on each side. Halothane was then withdrawn and anesthesia maintained with $30 \% \mathrm{~N}_{2} \mathrm{O}+70 \% \mathrm{O}_{2}$. No surgical procedures were performed after withdrawal of halothane nor were any experimental procedures performed that have not been tolerated by unanesthetized animals. The experiment began approximately $60 \mathrm{~min}$ after withdrawal of halothane.

Stimulation of sympathetic nerves. Most of the sympathetic fibers innervating the cerebral vasculature originate from the ipsilateral superior cervical sympathetic ganglion. Thus the effect of unilateral electrical stimulation of the superior cervical sympathetic ganglion on cerebral vessels is primarily on the ipsilateral hemibrain (10), whereas the contralateral hemibrain can serve as control when measuring $\mathrm{CBF}$ with microspheres. In the present experiments the preganglionic nerves were stimulated on the right side while the left side was unstimulated and served as control. Stimulation parameters were $15 \mathrm{~Hz}, 15 \mathrm{~V}, 3 \mathrm{~ms}$. Stimulation was continued for 1-2 min and CBF measured between 45 and $90 \mathrm{~s}$ of the stimulation period.

Measurement of $C B F$. Blood flow was measured with the tracer microsphere technique (11). Microspheres $(15.0+1.0 \mu \mathrm{m})$ labeled with $141-\mathrm{Ce}, 85-\mathrm{Sr}, 46-\mathrm{Sc}$ (3M, St. Paul, MN), or 113-Sn 
(New England Nuclear, Boston, MA) were used. Stock solutions were sonicated for $5 \mathrm{~min}$ and shaken vigorously on a vortex mixer for 2-5 min. Approximately $0.7-1.2$ million microspheres were placed into specially prepared injection vials (11) and shaken again on a vortex mixer prior to injection. The contents of the injection vial were flushed into the left atrium over a period of 15-30 s. Reference arterial blood was withdrawn from the brachial artery for $10 \mathrm{~s}$ prior to, during, and for $60 \mathrm{~s}$ after the microsphere injection at a rate of $0.97 \mathrm{ml} / \mathrm{min}$.

At the end of the experiment, the animal was killed by intravenous injection of $\mathrm{KCl}$, and the brain was removed and sectioned into right and left cerebrum, caudate nucleus, hippocampus, thalamus-hypothalamus, midbrain, cerebellum, pons, and medulla. In addition to the brain, the left and right choriod plexus (from the lateral ventricles) and the left and right masseter muscles were also removed. Tissues were weighed and placed into counting vials along with reference bloods. Counting vials were filled to a height of less than $2.5 \mathrm{~cm}$ to minimize geometrical counting error.

Tissues and reference bloods were counted for $5 \mathrm{~min}$ with a three-channel $\gamma$-counter (Beckman Instruments, Fullerton, CA). Energy windows were set at 125-170, 370-430, 460-550, and 820-1060 KeV for 141-Ce, 113-Sn, 85-Sr, and 46-Sc, respectively. Nuclide separation was performed using standard methods for differential spectrometry (11). Blood flow was calculated with the formula $\dot{Q}=\mathrm{At} * \dot{\mathrm{Q}} / \mathrm{Ar} / \mathrm{Wt} * 100$, where $\dot{\mathrm{Q}}$ is flow to tissue in $\mathrm{ml} / \mathrm{min} / 100 \mathrm{~g}$. Qr, At, Ar, and Wt are the reference blood withdrawal rate, activity of the tissue, activity of the reference blood, and the tissue weight, respectively. Cardiac output (ml/ $\mathrm{kg} / \mathrm{min}$ ) was calculated as cardiac output $=\mathrm{Ai} * \dot{\mathrm{Qr}} / \mathrm{Ar} /$ body weight, where Ai is the total activity injected. Total activity was calculated from the volume of the stock microsphere solution injected.

The use of $15 \mu \mathrm{m}$ microspheres to measure blood flow in the choroid plexus has not received adequate validation. One problem is that due to its small size ( $40 \mathrm{mg}$ ) the choroid plexus does not trap adequate numbers of microspheres resulting in larger variability of blood flow measurements (12). In the control conditions, a mean of $256 \pm 29$ microspheres were lodged in a single choroid plexus. Despite these theoretical limitations, in- dependent measurements of right versus left choroid plexus flow are well correlated $(r=0.74)$ during control conditions and thus the mean flow values for right and left choroid plexus at control are identical (Table 1), suggesting that the design of this study (right versus left comparisons) offers adequate sensitivity to detect unilateral changes in flow to this structure. Perhaps a more serious problem is that of sphere shunting. It is possible that a sizeable portion of $15 \mu \mathrm{m}$ spheres are not completely trapped by the choroid plexus. If significant numbers of microspheres pass through the choroid plexus to the venous circulation then flow would be underestimated. In this respect, an alternative interpretation of our data would be that sympathetic stimulation resulted in vasodilation so that fewer microspheres were trapped in the plexus. However, such an interpretation is unlikely because we have shown that vasodilator agents (adenosine) resulted in an increased number of trapped spheres and increased calculated blood flow to the choroid plexus (unpublished results) of lambs.

Since the brain regions were separated into right and left sides, some of the smaller structures often had less than 385 microspheres as well. This occurred most often in the cerebral white matter $(63 \%$ of the cases), pons $(55 \%)$, and masseter muscle $(45 \%)$ samples and less often in the hippocampus (28\%), caudate nucleus $(20 \%)$, and medulla ( $8 \%)$. Nevertheless, as was the case for the choroid plexus, independent measurements of right and left sides during control conditions, in these regions as well show mean values differing by less than $4 \%$ (Table 1 ) suggesting that unilateral differences in flow can be detected with considerable sensitivity.

Experimental protocol. In order to examine the efficacy of sympathetic nerves on CBF during postnatal development, the piglets were separated into five groups according to postnatal age. These groups were $2-3,4-6,7-9,10-15$, and $>15$ days of age. CBF was measured during baseline (no stimulation) and again following 45-90 s of unilateral sympathetic nerve stimulation. Arterial blood was sampled prior to each CBF measurement and analyzed for blood gases and pH using standard Radiometer electrodes. Mean arterial blood pressure was continuously monitored using a strain gauge (Statham P23d) and recorded on a Grass polygraph.

In five piglets (mean age $=9.4 \pm 3.6$ days) in addition to the

Table 1. Effect of sympathetic nerve stimulation on regional $C B F$ in newborn piglets (mean $\pm S E)^{*}$

\begin{tabular}{lccc}
\hline & $\begin{array}{c}\text { Control } \\
(n=41)\end{array}$ & $\begin{array}{c}\text { Normocapnic } \\
\text { stimulation } \\
(n=41)\end{array}$ & $\begin{array}{c}\text { Hypercapnic } \\
\text { stimulation } \\
(n=5)\end{array}$ \\
\hline Pacos $(\mathrm{mm} \mathrm{Hg})$ & $38 \pm 2$ & $37 \pm 3$ & $64 \pm 5 \div$ \\
Blood pressure $(\mathrm{mm} \mathrm{Hg})$ & $90 \pm 2$ & $89 \pm 2$ & $102 \pm 7$ \\
Cardiac output $(\mathrm{ml} / \mathrm{kg} / \mathrm{min})$ & $206 \pm 15$ & $210 \pm 21$ & $341 \pm 30$
\end{tabular}

Blood flows $(\mathrm{ml} / \mathrm{min} / 100 \mathrm{~g})$

\begin{tabular}{lcccccc} 
& Left & Right & Left & Right & Left & Right \\
\cline { 2 - 6 } Cerebrum & $79 \pm 7$ & $78 \pm 8$ & $74 \pm 4$ & $62 \pm 4 \dagger$ & $262 \pm 64 \ddagger$ & $167 \pm 28 \dagger$ \\
$\quad$ Gray matter & $80 \pm 7$ & $78 \pm 8$ & $74 \pm 4$ & $60 \pm 4 \dagger$ & $267 \pm 55 \ddagger$ & $169 \pm 28 \dagger$ \\
$\quad$ White matter & $37 \pm 3$ & $36 \pm 4$ & $35 \pm 2$ & $32 \pm 2 \dagger$ & $111 \pm 20 \ddagger$ & $83 \pm 10 \dagger$ \\
Caudate nucleus & $70 \pm 6$ & $67 \pm 6$ & $66 \pm 4$ & $64 \pm 4$ & $287 \pm 57 \ddagger$ & $235 \pm 44 \dagger$ \\
Hippocampus & $47 \pm 8$ & $48 \pm 4$ & $45 \pm 2$ & $41 \pm 2 \dagger$ & $208 \pm 42 \ddagger$ & $156 \pm 28 \dagger$ \\
Thalamus-hypothalamus & $85 \pm 10$ & $85 \pm 10$ & $82 \pm 5$ & $81 \pm 5$ & $419 \pm 83 \ddagger$ & $374 \pm 57$ \\
Midbrain & $84 \pm 9$ & $85 \pm 10$ & $81 \pm 6$ & $79 \pm 6$ & $454 \pm 80 \ddagger$ & $407 \pm 78$ \\
Pons & $78 \pm 9$ & $77 \pm 10$ & $71 \pm 6$ & $71 \pm 5$ & $405 \pm 80 \ddagger$ & $401 \pm 78$ \\
Medulla & $73 \pm 9$ & $75 \pm 9$ & $74 \pm 5$ & $73 \pm 5$ & $433 \pm 85 \ddagger$ & $409 \pm 77$ \\
Cercbellum & $78 \pm 7$ & $76 \pm 7$ & $64 \pm 5$ & $73 \pm 5$ & $345 \pm 79 \ddagger$ & $285 \pm 50$ \\
Choroid plexus & $281 \pm 25$ & $280 \pm 28$ & $258 \pm 26$ & $126 \pm 15 \dagger$ & $576 \pm 112$ & $183 \pm 87 \dagger$ \\
Messeter muscle & $21 \pm 2$ & $21 \pm 2$ & $20 \pm 2$ & $1 \pm 1 \dagger$ & $32 \pm 10$ & $1 \pm 1 \dagger$ \\
\hline
\end{tabular}

* PaCO ${ }_{2}$ arterial blood partial pressure of $\mathrm{CO}_{2}$. During control, sympathetic nerves were not stimulated. During normocapnic and hypercapnic stimulation, the right superior cervical sympathetic trunk was electrically stimulated for $45 \mathrm{~s}$ prior to and during measurement of blood flow. The effects of sympathetic nerve stimulation are represented by differences in blood flow between the unstimulated (left) and stimulated (right) side.

$†$ Right side significantly different from left side. $p<0.05$

$\ddagger$ Significantly different from control $p<0.05$ (this comparison was made only for the unstimulated side). 
above CBF measurements the effect of sympathetic nerve stimulation on CBF was determined during hypercapnia. Following the baseline, and sympathetic stimulation (during normocapnia) measurements. $\mathrm{CO}_{2}$ was added to the inspiratory gas mixture such that arterial $\mathrm{PCO}_{2}$ was elevated from $35-40$ to $>60 \mathrm{~mm} \mathrm{Hg}$ for $10 \mathrm{~min}$. Then an arterial blood sample was taken, the right sympathetic trunk was stimulated and CBF measured for a third time.

In four piglets $(4,5,6$, and 21 days of age), the effect of alterations in stimulation frequency on $\mathrm{CBF}$ was determined. Following baseline measurements, the sympathetic nerves were stimulated unilaterally as described above except that stimulation frequency was altered; 4, 8, and $16 \mathrm{~Hz}$. Arterial blood was sampled and CBF measured at each stimulation frequency. The sequence by which the frequencies were administered was randomized and $10 \mathrm{~min}$ allowed between each stimulation.

Statistical analwsis. All data are reported as means \pm SEM. Comparisons between right (stimulated) and left (unstimulated) sides were made using paired $t$ tests. A one-way analysis of variance was used for comparisons between postnatal age groups. The effects of hypercapnia were compared to control and normocapnic stimulation by a onc-way analysis of variance with repeated measures followed by Student-Newman-Kuels test for differences between means when the $\mathrm{F}$ value was significant. $p$ $\leq 0.05$ was considered to be statistically significant.

\section{RESULTS}

The effect of unilateral sympathetic stimulation $(15 \mathrm{~Hz})$ on regional CBF, blood pressure and cardiac output are presented in Table 1 and Figure 1. Data are from all 41 piglets combined Arterial blood gases were maintained constant $\left(\mathrm{PaO}_{2}>100 \mathrm{~mm}\right.$ $\mathrm{Hg}$ ) during control and during normocapnic stimulation. There were no differences between left and right regional CBF or masseter muscle flow during control (no stimulation). Stimulation of the right sympathetic trunk, during normocapnia, reduced blood flow to the right cerebrum $(-15 \pm 2 \%)$, hippocampus $(-9$ $\pm 2 \%)$, choroid plexus $(-50 \pm 5 \%)$, and masseter muscle $(-93$ $\pm 2 \%)$. Blood flow to the caudate nucleus, thalamus-hypothalamus, midbrain, pons, medulla, and cerebellum were not affected.

During hypercapnia ( $\mathrm{PaCO} \mathrm{O}_{2}=64 \mathrm{~mm} \mathrm{Hg}$ ) flow to the unstimulated side increased 2- to 4-fold in all brain regions except in the choroid plexus. On the stimulated side (right) flow was

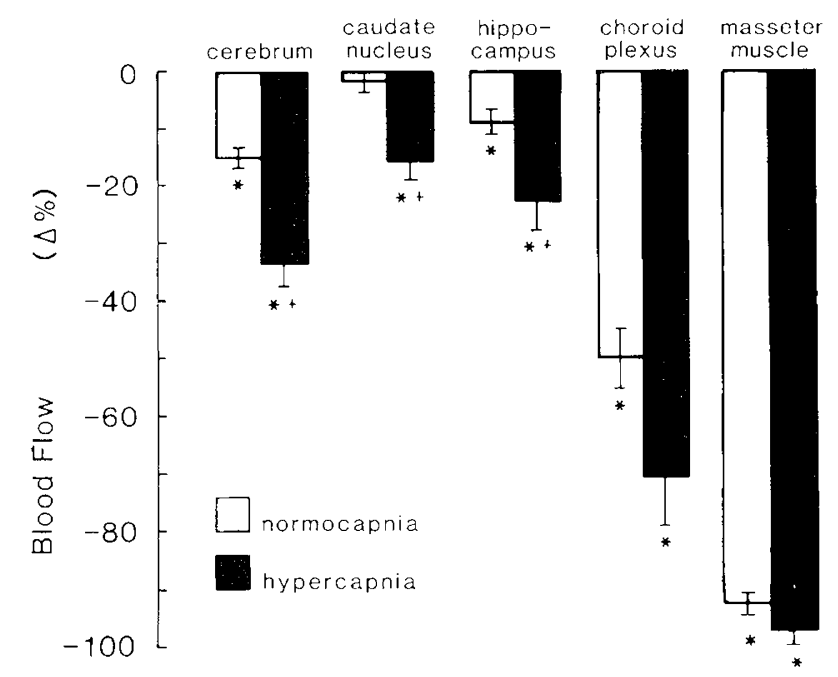

Fig. 1. Eiffect of electrical stimulation ( $15 \mathrm{~h} \% .15 \mathrm{~V} .3 \mathrm{~ms})$ of the right cervical sympathetic trunk on regional cerebral blood flow in the ipsilateral hemibrain during normocapnia $\left(\operatorname{PaC}()_{2}=38 \mathrm{~mm} \mathrm{Hg} . n=41\right)$ and hypercapnia ( $\left.\mathrm{PaC}()_{2}=64 \mathrm{~mm} \mathrm{Hg} . n=5\right) . \triangle \%$ is the percent change in flow $=($ right-left $) / \mathrm{left} * 100$. Values are mean \pm SE. * significantly different from zero, $\dot{\dagger}$ significantly different from normocapnia, $p \leq 0.05$.

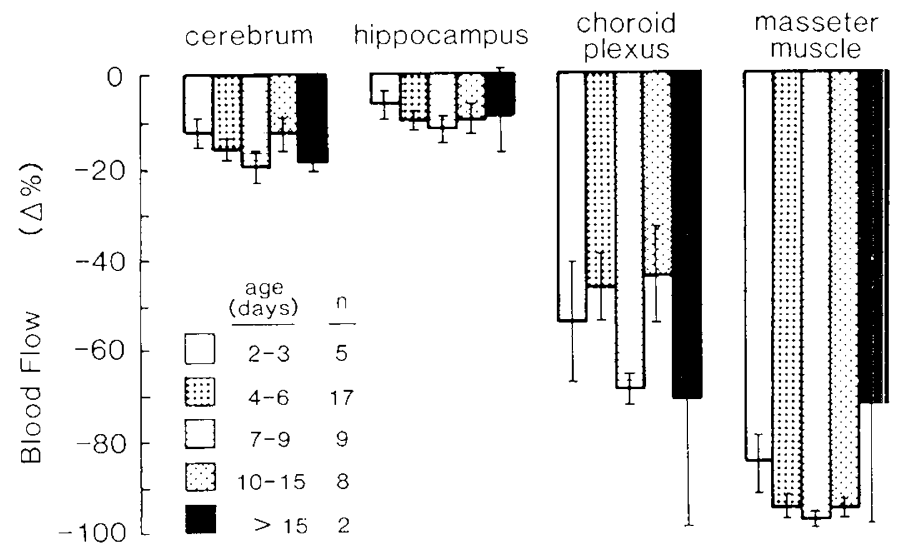

Fig. 2. Effect of electrical stimulation $(15 \mathrm{~Hz}, 15 \mathrm{~V}, 3 \mathrm{~ms})$ of the right cervical sympathetic trunk on regional cerebral blood flow in the hemibrain ipsilateral to stimulation at various postnatal ages in newbor:? piglets. $\lrcorner \%$ is the percent change in flow $=($ right-left $) /$ left $* 100$. Values are means \pm SE. There were no statistically significant differences noted between any age group in any of the four regions examined.

significantly less than the control side in the cerebrum, caudate nucleus, hippocampus, choroid plexus, and masseter muscle during hypercapnia. Although the mean values for choroid plexus flow and cardiac output appear to be elevated during hypercapnia, these changes were not significant when compared to the paired control values of those five animals (cardiac output $=273 \pm 53 \mathrm{ml} / \mathrm{kg} / \mathrm{min}$; choroid plexus $=446 \pm 123 \mathrm{ml} / \mathrm{min} /$ $100 \mathrm{~g}$ ). It is possible, however, that these increases were indeed real but could not be detected with so few animals since the type II error was high $(>85 \%)$ for both variables.

Figure 1 illustrates the effect of hypercapnia on the efficacy of sympathetic stimulation in those tissues where sympathetic vasoconstriction was observed. Hypercapnia augmented the magnitude of the reduction in blood flow to the cerebrum, hippocampus, and caudate nucleus (cerebral tissues) yet effects in the choroid plexus and masseter were not altered.

The effect of sympathetic stimulation on regional $\mathrm{CBF}$ as a function of postnatal age is depicted in Figure 2. In all four regions where flow was decreased (cerebrum, hippocampus, choroid plexus, and masseter muscle) sympathetic stimulation reduced flow significantly in the youngest age group (2-3 days) and there were no differences noted with increasing age (up to 15 days) in any of the brain regions. Also shown in Figure 2 are data from two older animals, 21 and 23 days of age in which reductions regional CBF were seen as well ( $>15$ days group).

The effect of increasing stimulus frequencies $(4,8$, and $16 \mathrm{~Hz})$ on the blood flow to the cerebrum are shown in Figure 3 . The magnitude of the reduction in flow to the stimulated side increased with stimulation frequency. Significant decreases in flow to the ipsilateral cerebrum were noted at $8(-12 \pm 4 \%)$ and 16 $\mathrm{Hz}(-14 \pm 5 \%)$.

\section{DISCUSSION}

The autonomic nervous system in a number of vascular beds is immature at birth and develops over the postnatal period, eventually reaching adult characteristics. In the rabbit myocardium, for example, sympathetic innervation occurs postnatally and catecholamine levels do not reach adult levels until 3-4 wk of age (13), while in lambs, myocardial neural development occurs largely during the last half of gestation and development continues postnatally (14). In the canine hindlimb, vasoconstrictor responses to sympathetic stimulation do not appear until 4 wk of age (15). Therefore, responses to sympathetic activation are generally small in neonates compared to adults.

While the importance of sympathetic nerves in the cerebral 


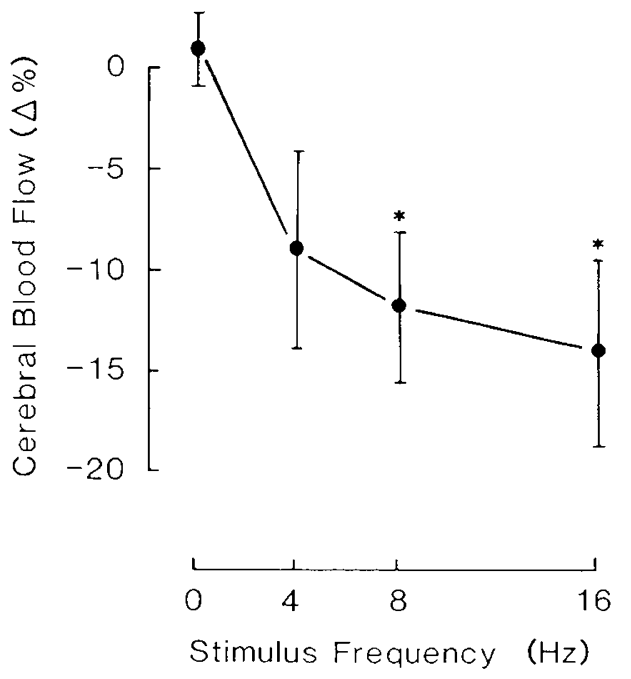

Fig. 3. Effect of increasing frequency of electrical stimulation of the right cervical sympathetic trunk on blood flow to the ipsilateral cerebrum in newborn piglets. $\lrcorner \%$ is the percent change in flow $=$ (right cerebrumleft cerebrum)/left cerebrum $* 100$. Values are means + SE, $n=4$. * signiticantly different from the unstimulated (left) side. $p<0.05$.

circulation is a subject of considerable interest and controversy in adult animals, little is known about the developmental aspects of cerebral sympathetic innervation and function. Studies in rodents $(2,16)$ and rabbits (9) indicate that $\alpha$ and $\beta$ adrenergic receptor numbers as well as contractile responses of isolated basilar artery to various agents, including norepinephrine, increase with postnatal age suggesting that adrenergic mechanisms are relatively immature during the neonatal period in the cerebral circulation as well. In species that are generally more mature at birth, however, sympathetic nerves may have a large influence on the cerebral circulation during the neonatal period. In baboons (17), isolated cerebral arteries of neonates are 10 times more sensitive to adrenergic agonists than adult cerebral arteries or arteries from other vascular beds of the same neonate. In asphyxiated puppies, the $\alpha$-antagonist, phentolamine, reduced vascular resistance in the cerebrum suggesting a component of adrenergic mediated vasoconstriction (4), yet adult dogs appear to be one species where effects of sympathetic stimulation on CBF are smallest (18). In lambs, maximal electrical stimulation of sympathetic nerves reduced flow during hypoxia by $35 \%$ in the cerebrum (5). The effect of sympathetic nerves on CBF in the normoxic, normocapnic newborn animals has not been previously studicd.

The present study has shown that sympathetic nerve stimulation reduced $\mathrm{CBF}$ in the normoxic, eucapnic newborn piglet, with no clear increase or decrease in sympathetic efficacy over the first 23 days of extrauterine life. The influence of sympathetic nerves was augmented, however, during hypercapnic hyperemia. The degree of cerebral vasoconstriction was dependent on stimulation frequency. These data suggest that, in piglets, the efferent sympathetic pathway, i.e. postganglionic neuron and neuromuscular synaptic transmission mechanisms, are functional at 2 days of age and efficacy of sympathetic activation does not increase over the first weeks of life. In addition, because the sympathetic trunk was stimulated preganglionically, the present study suggests that synaptic transmission in the superior sympathetic ganglion is functionally developed in the newborn piglet unlike rats (16) where preganglionic stimulation does not result in postganglionic action potentials until $1 \mathrm{wk}$ of age. Younger animals were not examined in the present study, however, Busija et al. (19) have shown that sympathetic stimulation constricts pial arterioles in 1 -day-old piglets and so it would appear that sympathetic nerves in the cerebral circulation are well developed at birth.
In adults, the effect of sympathetic nerves on CBF appear to be species-dependent. In normocapnic dogs, cats, and rabbits, $\mathrm{CBF}$ was not altered by sympathetic stimulation $(18,20)$ but in monkeys flow was reduced by $26 \%$ (18). The $15 \%$ decrease in CBF observed during unilateral sympathetic stimulation in the present study is considerable compared to those adult studies. Similarly, sympathetic stimulation causes comparatively large decreases in pial arterial caliber in the newborn piglet (19). Whether the magnitude of the effect of sympathetic nerves is due to species differences or to developmental age cannot be determined because data for adult pigs are not available. Isolated adult pig cerebral arteries in vitro, however, respond to topical norepinephrine or transmural electrical stimulation by vasodilation $(21,22)$. In addition, histochemical and radioligand binding studies have failed to establish the presence of $\alpha_{1}$ adrenergic receptors in adult pig cerebral arteries, although $\beta_{1}$ and $\alpha_{2}$ adrenoceptors are present $(23,24)$. The present studies and those of Busija et al. (19) clearly demonstrate sympathetically mediated vasoconstriction in the newborn piglet, suggesting major differences between neonates and adults in this species.

Sympathetic vasoconstrictor influences on CBF were more pronounced during hypercapnia in these piglets even though acidosis inhibits both presynaptic release of norepinephrine as well as vascular responsiveness to norepinephrine (25-27). The mechanism by which $\mathrm{CO}_{2}$ potentiates sympathetic effects on cerebral blood flow as suggested by Harper et al. (6), is explained by differences in vascular control mechanisms within the cerebral circulatory bed. During sympathetic stimulation, only larger arterioles, primarily in the pial circulation constrict while changes in $\mathrm{CBF}$ are small or negligible because smaller intraparenchymal vessels, under local metabolic control, compensate by vasodilation. During hypercapnia, intraparenchymal vessels are already dilated and cannot compensate for vasoconstriction in large, upstream vessels; thus total flow is decreased when sympathetic nerves are stimulated. If in the newborn, such compensatory vasodilation by intraparenchymal vessels were lacking or diminished because of immaturity of responsiveness to vasodilator stimuli (7-9), then effects of sympathetic nerves would appear to be larger. The findings of the present study indicate that this is not the case in piglets. The reduction in CBF was augmented by $\mathrm{CO}_{2}$ from $15 \%$ in normocapnia to $34 \%$ during hypercapnia, suggesting that under normocapnic conditions, downstream compensatory vasodilation attenuated, by one-half, the effect of sympathetic nerves on $\mathrm{CBF}$.

During normocapnia, sympathetic stimulation reduced flow in the cerebrum, hippocampus, and choroid plexus while other regions examined (caudate nucleus, thalamus, midbrain, pons, cerebellum, and medulla) were not affected. During hypercapnia, sympathetic stimulation decreased flow to the caudate nucleus as well. In adult cats, sympathetic innervation is less dense in hindbrain regions than forebrain regions (28). The regional effect of sympathetic stimulation on $\mathrm{CBF}$ in the present study suggests a similar pattern of innervation density in the brain of the newborn piglet. Effects of unilateral stimulation on flow to hindbrain structures supplied via the basilar artery, however, may not be detected using right versus left comparisons since any constriction in this artery or upstream vessels would reduce flow to each side equally. Consequently, these data cannot be interpreted to suggest that no sympathetic effects occur in the brainstem and cerebellum.

The most profound effect of sympathetic nerve stimulation was noted in the choroid plexus where flow was reduced by $50 \%$ demonstrating that sympathetic innervation in this species is present at birth unlike neonatal rabbits, where adrenergic innervation develops over three weeks postnatally and the plexus in the lateral ventricles are the last to receive innervation (29). Early studies in adult rabbits showed no effect of sympathetic nerves on choroid plexus blood flow (30-20), however, significant constriction was noted following $\alpha_{2}$ adrenergic blockade (32), suggesting presynaptic autoinhibition in this structure. The large 
effect observed in the present study may relate to the relatively dense innervation of pig choroidal arteries compared to other species (29) and suggests a potential role of these nerves in regulating choroidal blood flow or cerebrospinal fluid formation in the newborn.

The question as to the role of the sympathetic nervous system in the cerebral circulation in the newborn is an important one. The newborn period is often associated with various degrees of stress due to respiratory and circulatory difficulties. Studies from adults suggest that sympathetic nerves in brain vessels may protect cerebral capillaries from damage by acute changes in blood pressure $(18,33)$ or that they may exert a trophic influence on brain arteries $(3,31)$. During hypoxia or hypercapnia, however, activation of these nerves may limit increases in flow and thus have a deleterious effect on the available oxygen. The impact of physiological reflex activation of sympathetic nerves in the newborn CBF remains uncertain. There have been few studies as to what physiological conditions might result in activation of these nerves in the neonate. In a previous study the CBF response to hypoxia was not altered by $\alpha$, adrenergic receptor blockade in lambs (5), yet in asphyxiated puppies, $\alpha$ adrenergic blockade decreased cerebrovascular resistance (4). The present study has demonstrated that in piglets, functional sympathetic mechanisms are established in several brain regions at birth and when electrically stimulated significantly alter $\mathrm{CBF}$.

Acknowledgments. The authors thank David Frank and Ben Deratzou for technical assistance and Dr. David Busija for reviewing this manuscript. These results were presented in part at the Federation of American Societies for Experimental Biology meetings in St. Louis, MO. April 1984.

\section{REFERENCES}

1. Mirkin BL 1972 Ontogenesis of the adrenergic nervous system: functional and pharmacologic implications. Fed Proc 31:65-73

2. Kobayashi H. Cayaniga A. Spano P. Trabucchi M 1982 Ontogenesis of $\alpha x$ and 3 receptors located on cerebral microvessels. Brain Res 242.358-360

3. Kobayashi S. Tsukahara K. Sugita K. Matsuo K. Vagata T 1981 Histochemical studies on the postnatal development of autonomic nerves in mice cerebral arteries. Histochemistry $73: 15-20$

4. Hernandez MJ. Hawkins RA. Brennan RW 1982 Sympathetic control of regional cerebral blood flow in the asphyxiated newborn dog. In: Heistad DD. Marcus ML. (eds) Cerebral Blood Flow. Fffects of Nerves and Neurotransmitters. Elsevier. New York. pp 359-366

5. Wagerle LC. Heffernan TM. Sacks I.M. Delivoria-Papadopoulos M 1983 Sympathetic effect on cerebral blood flow regulation in hypoxic newborn lambs. Am J Physiol 245:H487-H494

6. Harper AM. Deshmukh VD. Rowan JO, Jennet WB 1972 The influence of sympathetic nervous activity on cerebral blood flow. Arch Ncurol 27:1-6

7. Reivich M. Brann Jr AW. Shapiro H. Rawson J. Sano N 1971/72 Reactivity of cerebral vessels to $\mathrm{CO}_{2}$ in the newborn rhesus monkey. Eur Neurol 6:132136

8. Rosenberg AM, Jones Jr MD. Traystman RJ. Simmons MA. Moltini RA 1982 Response of cerebral blood flow to changes in $\mathrm{PCO}_{2}$ in fetal, newborn, and adult sheep. Am J Physiol 242:H862-H866

9. Toda N. Hayashi S 1979 Age dependent alteration in the response of isolated rabbit basilar arteries to vasoactive agents. J Pharmacol Exp Ther 211:716721

10. Heistad DD. Marcus ML. Busija DW 1980 Measurement of cerebral blood flow in experimental animals with microspheres: applications of the method. In: Passinncau JV Hawkins RA Lust WD Wclsh FA (cds) Ccrebral Metabolism and Neural Function. Williams \& Wilkins. Baltimore. pp 202-210
11. Heymann MA, Payne BD. Hoffman JIE. Rudolph AM 1977 Blood flow measurements with radionuclide labeled particles. Prog Cardiovasc Dis 20:55-79

12. Buckberg GD. Luck JC. Payne DB. Hoffman JIE, Archic J. Fixler DE 1977 Some sources of error in measuring regional blood flow with radionuclide labeled particles. Prog Cardiovasc Dis 20:55-79

13. Friedman WF. Pool PE, Jacobowit\% D. Seagren SC, Braunwald E 1968 Sympathetic innervation of the developing rabbit heart. Biochemical and histochemical comparisons of fetal, neonatal and adult myocardium. Cire Res 23:25-32

14. Lebowitz EA. Novick JS, Rudolph AM 1972 Development of myocardial sympathetic innervation in the fetal lamb. Pediatr Res 6:887-893

15. Boatman DL, Shaffer RA. Dixon RL, Brody MJ 1965 Function of vascular smooth muscle and its sympathetic innervation in the newborn dog. J Clin Invest 44:241-246

16. Mills E. Smith PG 1983 Functional development of the cervical sympathetic pathway in the neonatal rat. Fed Proc 42:1639-1641

17. Hayashi S. Park MK. Kuehl TJ 1984 Higher sensitivity of cerebral arteries isolated from premature and newborn baboons to adrenergic and cholinergic stimulation. Life Sci 35:253-260

18. Heistad DD, Marcus ML. Gross PM 1978 Effects of svmpathetic nerves on cerebral vessels in dog. cat and monkey. Am J Physiol 235:H544-H552

19. Busija DW, Leffler CW. Wagerle LC 1985 Responses of newborn pig pial arteries to sympathetic nervous stimulation and exogenous norepinephrine. Pediatr Res 19:1210-1214

20. Linder J 1982 Effects of cervical sympathetic stimulation on cerebral and ocular blood flow during hemorrhagic hypotension and moderate hypoxia. Acta Physiol Scand 114:379-386

21. Lee T, Kinkhead I.R. Sarwinski S 1982 Norepinephrine and acetylcholine transmitter mechanisms in large cerebral arteries of the pig. J Cereb Blood Flow Mctab 2:439-450

22. Winquist RJ, Webb RC. Bohr DF 1982 Relaxation to transmural nerve stimulation and exogenously added norepinephrine in porcine cerebral vesseis. Circ Res 51:769-776

23. Friedman AH. Davies JN 1980 Identification and characterization of adrene:gic receptors and catecholamine stimulated adenylatc cyclase in hog pial membranes. Brain Res 183:89-102

24. Harik SI, Sharma JK. Wetherbee JR, Warren RH, Banerjec SP 1981 Adrenergic and cholinergic receptors of cerebral microvessels. J Cereb Blood Flow Metab 1:329-338

25. Navari R. Wei EP, Kontos HA. Patterson Jr JL 1978 Comparison of the open skull and cranial window preparations in the study of the cerebral microcirculation. Microvas Res 16:304-315

26. Puig M. Kipekur SM 1971 Inhibitory effect of low $\mathrm{pH}$ on norepinephrine release. J Pharmacol Exp Ther 176:134-138

27. Verhaeghe RH, Lorenz RR, McGrath MA, Shepherd JT Vanhoutte PM 1978 Metabolic modulation of neurotransmitter release-adenosine, adenine nucleotides, potassium, hyperosmolarity and hydrogen ion. Fed Proc 37:208211

28. Edvinsson L. Mackenzic ET 1977 Amine mechanisms in the cerebral circulation. Pharmacol Rev 28:275-348

29. Lindvall M. Owman C 1981 Autonomic nerves in the mammalian choroid plexus and their influence on the formation of cerebrospinal fluid. J Cereb Blood Flow Mctab 1:245-266

30. Alm A 1977 The effect of sympathetic stimulation on blood flow through the uvea, retina. and optic nerve in monkevs (Macaca irus). Exp Eve Res 25:1924

31. Beausang-Linder M. Hultzcrantz E 1980 Early effects of cervical sympathetic stimulation on cercbral, ocular, and cochlear blood flow. Acta Physiol Scand 109:433-437

32. Linder J 1981 Cerebral and ocular blood flow during $x_{2}$-blockade: evidence for a modulated sympathetic response. Acta Physiol Scand 113:51 [-517

33. Bill A. Linder J 1976 Sympathetic control of cerebral blood flow in acute hypertension. Acta Physiol Scand 96:114-121

34. Bevan JA. Bevan RD 1977 Sympathetic control of the rabbit basilar artery. In: Owman C, Edvinsson L (eds) Neurogenic control of brain circulation. Permagon Press, Oxford, pp 285-293

35. Sadoshima S. Busija DW, Brody M. Heistad DD 1982 Protection against stroke by sympathetic nerves. In: Heistad DD. Marcus ML (eds) Cerebral Blood Flow: Effects of Nerves and Neurotransmitters. Elsevier, New York. pp 309315 